\title{
Third European Precious Metals Conference (Eurométaux) Florence, Italy, 17th - 19th September 1997
}

Papers spanned many topical areas of precious metals science and technology and the related commercial opportunities. There were seven half-day sessions in all and these were entitled 'Environment, Health and Safety' (Parts I and II), 'Precious Metals for Jewellery', 'Precious Metals Production', 'Precious Metals Applications', 'Sampling and Analysis' and 'Finance and Economic Issues'. A brief indication is given here of the content of those papers dealing with gold science and technology.

\section{Physical Metallurgy}

1.1 In the jewellery session Dr Andreas Zielonka (Forschungsinstitut für Edelmetalle und Metallchemie (FEM), Germany) set a stimulating tone by describing current work on improved wear resistance obtained with electroplated gold dispersion layers. The technique produces uniform surface colour and improved wear resistance without lowering the caratage for gold jewellery. The technique has also been successfully applied for gold contact materials and uses normal, commercially available electrolytes. Both titanium nitride and $0.25 \mu \mathrm{m}$ diamond particles have been successfully incorporated into gold jewellery. The degree of incorporation of the gold particles in the gold dispersion layers depends most of all on the concentration of particles in the electrolyte and the hydrodynamic conditions at the cathode. The incorporated particles are very uniformly distributed throughout the entire layer thickness and for the diamond case there is no change in the colour of the jewellery. This technology could, for example, be used as a $10-20 \mu \mathrm{m}$ coating for watch cases. The technique is now being applied for electroforming gold.

1.2 Dieter Ott, also from FEM, described the variables which must be considered when investment casting jewellery alloys. The method is suitable for industrial production of small to medium numbers of small- to medium-sized items, and can be used in dentistry for casting single pieces. The quality of the cast piece of jewellery depends both on the physics of the casting procedure and the metallurgy of the alloy, together with the thermal, mechanical and chemical properties of the investment material. The most frequent defect is porosity, which can be either gas or shrinkage porosity; the former is caused by chemical reactions with the investment binder or impurities and can be avoided by using optimum working conditions, but the latter is more difficult to avoid and each case must be treated on its merits. Other defects, such as insufficient form-filling and bad surface quality, can be avoided using a knowledge of the fundamental technical principles involved. This talk contained many good practical tips for obtaining sound items.

1.3 Dr Bernd Kempf (Degussa AG, Germany) described his recent work on the thermodynamic modelling of precious metal alloys containing significant proportions of gold, using thermodynamic software such as 'Chemsage'. The specially modelled data sets allow calculation of the stability of precipitated phases which are responsible for the hardening behaviour of alloys. This leads to a deeper understanding of the complex hardening mechanisms and hence allows a reduction of experimental work. A comparison of experimental results with thermodynamic stability calculations gives good correlations for the gold alloys evaluated to date. We plan to publish this paper in full in the next issue of Gold Bulletin. 
1.4 Dr David Lupton, Heraeus, Germany, gave a talk entitled 'Platinum Group Metals for Very High Temperature Applications'. The strength of $\mathrm{Pt}-5 \%$ $\mathrm{Au}$ oxide dispersion hardened (DPH) alloy is considerably higher at $1600^{\circ} \mathrm{C}$ than that of the conventional $\mathrm{Pt} / 20 \% \mathrm{Rh}$ alloy at $1400^{\circ} \mathrm{C}$. Moreover, the rupture strength of the goldcontaining alloy is maintained over considerably longer test times, ie the strength advantage increases not only with temperature but also with time.

\section{Dentistry}

2.1 Dr Nadine Späth (Engelhard CLAL, France) described a new magnetic attachment system for total or partial overdentures composed of two biocompatible and corrosion resistant elements which are readily fixed within the patient's mouth. The magnet is encapsulated in a perfectly biocompatible precious metal alloy composed of $\mathrm{Au}$ 8, Pt 25, Pd 30 and $\mathrm{Ag} 37 \mathrm{wt} \%$ which allows transformation processing such as cold rolling and forming.

2.2 Two other papers relevant to dental applications were presented in the 'Environment, Health and Safety' Sessions. One was entitled 'The Biological Behaviour of Gold Alloys in the Human Body (Dr Martin Schuster, Heraeus Kulzer, Germany) and included demonstration that alloys based on precious metals, particularly gold, show great stability under conditions present in the patient's mouth. The risk of undesirable side effects was estimated from the corrosion rates and the known toxicological data of the components. Local toxic reactions are possible when the manufactured material is defective, but such occurrences can easily be avoided. It was mentioned that dentures made from naturally occurring gold have been used for at least 2,500 years (eg by the Etruscans). Dr Hartmut Hildebrand, Jean-Christophe Hornez and Nadine Späth of the Faculté de Medicine de Lille and Engelhard-CLAL, France, described biological and clinical effects of alloys used for dental restorations.

\section{Powder Metallurgy}

3.1 Recent developments in the technology of silver flake and powder for conducting adhesives and inks for electronics applications was described by Ernest Jost of Chemet Corporation, MA, USA (about to become part of Metalor). Much less gold ( 2 tons per annum in the US) is currently used for this sophisticated application than silver
(460 - 500 tons per annum in the US), but the question I ask is "Will the precision-led electronics scene lead to an increasingly higher demand for gold in these applications". Gold would surely be more durable than silver if appropriate technology were to be developed.

\section{Precious Metals Analysis}

4.1 Jean-Philippe Renard of Metalor, Switzerland described the effective use of X-Ray Fluorescence (XRF) analysis for 18 carat gold alloys. This method represents a significant time-saving compared with traditional fire-assay methods (1 vs $2 \frac{1}{2} \mathrm{hr}$ ). A full and accurate analysis can be obtained for a particular gold alloy but a new series of standards must be used for each new alloy. It is therefore more suitable for verifying the quality of production rather than individual jewellery products themselves.

4.2 D. Hofmans of Union Minière, Hoboken, Belgium described development of methods for precious metals analysis, including gold, using microwave/ICP techniques. The method is promising but needs to be improved by developing higher temperature / higher pressure closed vessel microwave systems. It could eventually prove to be a very acceptable high performance method.

\section{General Talks}

5.1 Fabio Torboli (Chief Executive, Europe, WGC) presented his talk entitled 'The Supply and Demand of Physical Gold and the Role of the European Industry'. Following the historical importance of the gold industry in Italy, Arezzo is today the single largest jewellery manufacturing area in Italy and probably the world with some 700 manufacturing units and an annual production output of almost 200 tonnes of fine gold. Europe will continue to play an important role in the future. The presentation consisted of four parts, ie an historical overview of gold supply and demand in Europe, a brief analysis of the most important business sectors, a more indepth evaluation of the jewellery industry, and a view of the future role of Europe.

5.2 Alexander Wiedow, EC, DG XXI, summarized current thinking on VAT on gold and discussed whether or not investment gold should be exempt. 